\title{
Parent Preference in the Attachment Exploration Balance in Infancy: An Experimental Psychoanalytic Approach
}

\author{
Merton A. Shill, Antal E. Solyom and Barrie M. Biven \\ Children's Psychiatric Hospital University of Michigan Medical Center, Ann Arbor, \\ Michigan 48109
}

\begin{abstract}
Fifteen 15-month old infants with mother as primary caretaker were observed in Ainsworth's Strange Situation modified to provide a simultaneous choice of mother or father during post-separation reunion episodes. Both exploratory and attachment behaviors were more significantly affected by separation from mother than from father, suggesting the greater importance of the mother as a secure base for exploration and as an attachment figure. The intrapsychic version of the parent most crucial to exploration and attachment at this age is that of mother, in whose absence the infant is not yet able to evoke the memory of the mother to sustain either exploratory behavior or the attachment bond adequately.
\end{abstract}

In their seminal paper on infant attachment research, Sroufe and Waters ${ }^{14}$ emphasized the importance of having regard to the content and meaning of the child's attachment behavior. Following Ainsworth and her collaborators ${ }^{1}$ they have secured the importance of the organizational approach to studying attachment in child development research. Ainsworth has furthermore emphasized that exploratory behavior should be related to the child's attachment to his/her mother and has accordingly formulated the now well-known concept of the "attachment-exploration balance"- the relative emphasis in the infant's behavior on exploratory.vs. attachment related behaviors and the importance of a secure relationship with a caretaking figure as a sine qua non for exploration. ${ }^{1}$

Although Ainsworth's approach is based on ethology and its applications to mother-infant interaction as developed by Bowlby, no specific hypotheses derived from this orientation have been tested in

\footnotetext{
An earlier version of this paper was presented at the Midwestern Psychological Association, Detroit, Michigan, May 1, 1981. This study was conducted while the authors were associated with the Child Analytic Study Program, Youth Services, Department of Psychiatry, University of Michigan (Humberto Nagera, M.D., Director). Dr. Shill was Senior Research Associate, Mr. Biven, Associate Director of the Program. and Dr. Solyom, Director of the Infant Study Section. Reprint requests should be addressed to Merton A. Shill, Ph.D., Child Study Center, 924-C Baldwin Ave., Ann Arbor, Michigan 48104.
} 
research to date, attachment theories being considered rather a "guide" to investigation. 1

The importance of investigating both the emotional and cognitive aspects of the development of the child within a theoretical framework has recently been emphasized. ${ }^{13}$ Osofsky and Connors ${ }^{12}$ have further observed that "the lack of a clear theoretical base has been a limiting factor in the development of frameworks for studying parent-infant relationships"' (p. 519).

The present paper is based on principles of psychoanalytic developmental psychology from which hypotheses have been derived in an attempt to predict the performance of dependent variables which measure exploration and attachment. We have drawn on both psychoanalytic developmental psychology and observational/ex. perimental studies in academic psychology in an attempt to ground findings concerning parent-infant relationships within a theoretical framework so as to permit prediction and construct validation.

The constructs explored in this paper deal primarily with the assumption in psychoanalytic psychology of the intrapsychic representation of significant figures in the infant's life (especially the mother and father) and the conditions under which this representation is rendered sufficiently unstable so as to induce the child to reestablish contact with a significant parental figure in a direct interpersonal manner, instead of being able to rely on the emotional sufficiency of the internal mental representation of the parent in the latter's absence. Winnicott ${ }^{18}$ refers to the capacity of the child to play independently of the direct presence of or interaction with the mother as "the capacity to be alone," which he considers a significant developmental milestone. This pilot study may be said to attempt to assess this capacity directly by determining whether it is the internalized representation of the mother or the father which is more affected by separation.

The child's interest in exploring the environment during separation puts the independence of the internal mental representation of the parent from exteroceptive stimulation to the test. This test is minimal where exploration occurs in the presence of the parent, maximal if the child is physically separated from the parent. This research is an attempt to use Ainsworth's strange situation to explore the attachmentexploration balance as constituting such a test. Other terms have been developed to describe this phenomenon. Furer ${ }^{6}$ suggests that during this period of instability in object representation, the internal representation of the mother requires "refueling" by interpersonal interaction with the parent. Following Piaget, Fraiberg ${ }^{4}$ has used the 
term "evocative memory" to describe the child's capacity for recalling without external stimulation the mental image of the mother, during stage VI of Piaget's stages of sensori-motor intelligence (18-24 months). We hypothesized that infants whose mothers were the primary caretaker would organize their attachment and exploratory behavior preferentially around her presence more significantly than around the presence of the father or a stranger. We assumed that the infant's relationship to the mother as primary caretaker would be more central to both its affective and cognitive development than that of either the father or a stranger such that the link between the affective and cognitive factors in development could be clearly demonstrated by. assessing the attachment-exploration balance in Ainsworth's Strange Situation. We therefore predicted that the attachment-exploration balance would shift in favor of attachment more significantly when the infants were separated from mother than when they were separated from father. This shift would be interpreted as evidence of an insufficiently secure internalized representation of the mother, whose evoked memory would otherwise sustain the mother-child attachment securely in the parents' absence. ${ }^{4}$ Given an inadequate capacity at this developmental stage for such evocative memory, the child will seek out alternative attachment figures in an interpersonal, "external" relationship for security.

Differences in reactions to separation from mother, father and stranger were expected to parallel previous research in showing the inability of the stranger to function adequately as a secure base in the Strange Situation, when compared to either parent.

\section{Previous Research}

Previous studies of differences in infant-mother vs. infant-father attachment and exploratory behavior have various shortcomings: They employ a global "play" variable an as index of exploration, confound order effects and parental preference in the data analysis or assess play inhibition at different stages of the Strange Situation procedure for different subjects, ${ }^{3.8}$ thus ignoring the cumulative increase in stress which most episodes in the Strange Situation procedure are designed to induce. ${ }^{1,11}$ Present studies do not furthermore provide the child with a simultaneous choice of mother or father in the experimental situation ${ }^{10,11}$ and/or use exclusively frequency rather than the more reliable qualitative measures of attachment. ${ }^{1,9,14}$

We have found no reported studies of the stability of the internal representation of a parenting figure in either the psychoanalytic or developmental psychology literatures. 


\section{Method and Procedure}

Fifteen 15-month old infants ( 9 boys and 6 girls) were selected from families volunteering to participate in infant research at the Children's Psychiatric Hospital, University of Michigan. Families were recruited by letter and the final sample was screened according to the research design criteria adopted: (mother as primary caretaker, normal medical history, native U.S. subject, number of same sex children already participating). Ten of the 15 families were from the major business/professional class, 4 from the medium business/ minor professional class and 1 from the skilled and semi-skilled worker class, all assessed according to Hollingshead's Four Factor Index of Social Position. ${ }^{7}$

Ainsworth's Strange Situation procedure was followed except for the inclusion of one additional episode allowing for separation from both parents sequentially and also providing for the simultaneous presence of both parents during reunion episodes (Table 1). A unit incorporating a one-way mirror flanked by two doors was specially constructed and used as a room divider, thus allowing both parents to re-enter the observation area of the room simultaneously to provide the child with a simultaneous choice of parents during reunion (Figure I). The order in which the parents left the child first at the end of Episode 3 was varied systematically such that father separated first for about half the sample (9), mother for the other half (6). Seating of the parents was also alternated systematically.

Ainsworth's frequency measures of exploration (exploratory locomotion, exploratory manipulation, and visual exploration) and qualitative ratings of attachment behaviors (proximity-seeking, contact-maintaining, resistance, avoidance, search and distance interaction) were applied by two independent judges to videotaped Strange Situation behavior. Interjudge agreement for exploratory locomotion was $89 \%$, for exploratory manipulation $94 \%$ and for visual exploration $92 \%$. Interjudge differences in the behavioral ratings of the quality of attachment were resolved in conference.

It should be noted that this study does not utilize Ainsworth's qualitative ratings of infant-parent attachment to classify infants into groups, based on the security of their attachment. The purpose of the present study was to assess the infant-parent preference in attachment and exploratory behavior utilizing Ainsworth's qualitative ratings which, like the classifications of security of attachment, have been found to be significantly more stable than frequency measures of attachment. ${ }^{16}$ A "between episodes" analysis of differentiality and preference in exploratory and attachment behavior in relation to mother, father and stranger was usually conducted by the Wilcoxon Signed-Ranks Matched Pairs Test; differences within episodes were assessed by the Mann-Whitney U Test. 
Table 1

Number of Persons

Eptsode Present

Duration

Brief Description of Action

1 Mother,

$30 \sec s$.

Experimenter introduces mother

Father, father and baby to the experi-

Baby, mental room, then leaves.

Experimenter

\begin{tabular}{|c|c|c|c|}
\hline 2 & $\begin{array}{l}\text { Mother, } \\
\text { Father, } \\
\text { Baby }\end{array}$ & 3 mins. & $\begin{array}{l}\text { Parents watch baby explore; if } \\
\text { necessary, play is stimulated } \\
\text { after } 2 \text { minutes. }\end{array}$ \\
\hline 3 & $\begin{array}{l}\text { Mother, } \\
\text { Father, } \\
\text { Baby and } \\
\text { Stranger }\end{array}$ & 3 mins. & $\begin{array}{l}\text { Stranger enters. First minute: } \\
\text { stranger silent. Second minute: } \\
\text { stranger converses with parents. } \\
\text { Third minute: - stranger approaches } \\
\text { baby. After } 3 \text { minutes one parent } \\
\text { leaves unobtrusively. }\end{array}$ \\
\hline 4 & $\begin{array}{l}\text { Mother or } \\
\text { Eather, } \\
\text { Baby and } \\
\text { Stranger }\end{array}$ & 3 mins. & $\begin{array}{l}\text { Remaining parent responds only if } \\
\text { baby initiates, May comfort baby } \\
\text { and then settle him again in play. } \\
\text { After } 3 \text { minutes, other parent } \\
\text { leaves unobtrusively. }\end{array}$ \\
\hline 5 & $\begin{array}{l}\text { Stranger, } \\
\text { and Baby }\end{array}$ & $\begin{array}{l}3 \text { mins. } \\
\text { or less }\end{array}$ & $\begin{array}{l}\text { First separation episode. } \\
\text { Stranger's behavior is geared } \\
\text { to that of baby. }\end{array}$ \\
\hline 6 & $\begin{array}{l}\text { Mother, } \\
\text { Father, } \\
\text { Baby }\end{array}$ & $\begin{array}{l}3 \text { mins. } \\
\text { or more }\end{array}$ & $\begin{array}{l}\text { First reunion episode. Pareats } \\
\text { greet and/or comfort baby, then } \\
\text { settle him again in play. Parents } \\
\text { then leave together, saying "bye- } \\
\text { bye." Stranger leaves unobtrusivel }\end{array}$ \\
\hline 7 & $\begin{array}{l}\text { Baby } \\
\text { alone }\end{array}$ & $\begin{array}{l}3 \text { mins. } \\
\text { or less }\end{array}$ & Second separation episode. \\
\hline 8 & $\begin{array}{l}\text { Stranger, } \\
\text { and Baby }\end{array}$ & $\begin{array}{l}3 \text { mins. } \\
\text { or less }\end{array}$ & $\begin{array}{l}\text { Continuation of second separation. } \\
\text { Stranger enters and gears her } \\
\text { behavior to that of baby. }\end{array}$ \\
\hline 9 & $\begin{array}{l}\text { Mother, } \\
\text { Father, } \\
\text { and Baby }\end{array}$ & 3 mins. & $\begin{array}{l}\text { Second reunion episode. Parents } \\
\text { enter simultaneously, greet baby, } \\
\text { baby may be comforted or cuddled } \\
\text { by parent of his preference. } \\
\text { Stranger leaves unobtrusively. }\end{array}$ \\
\hline
\end{tabular}




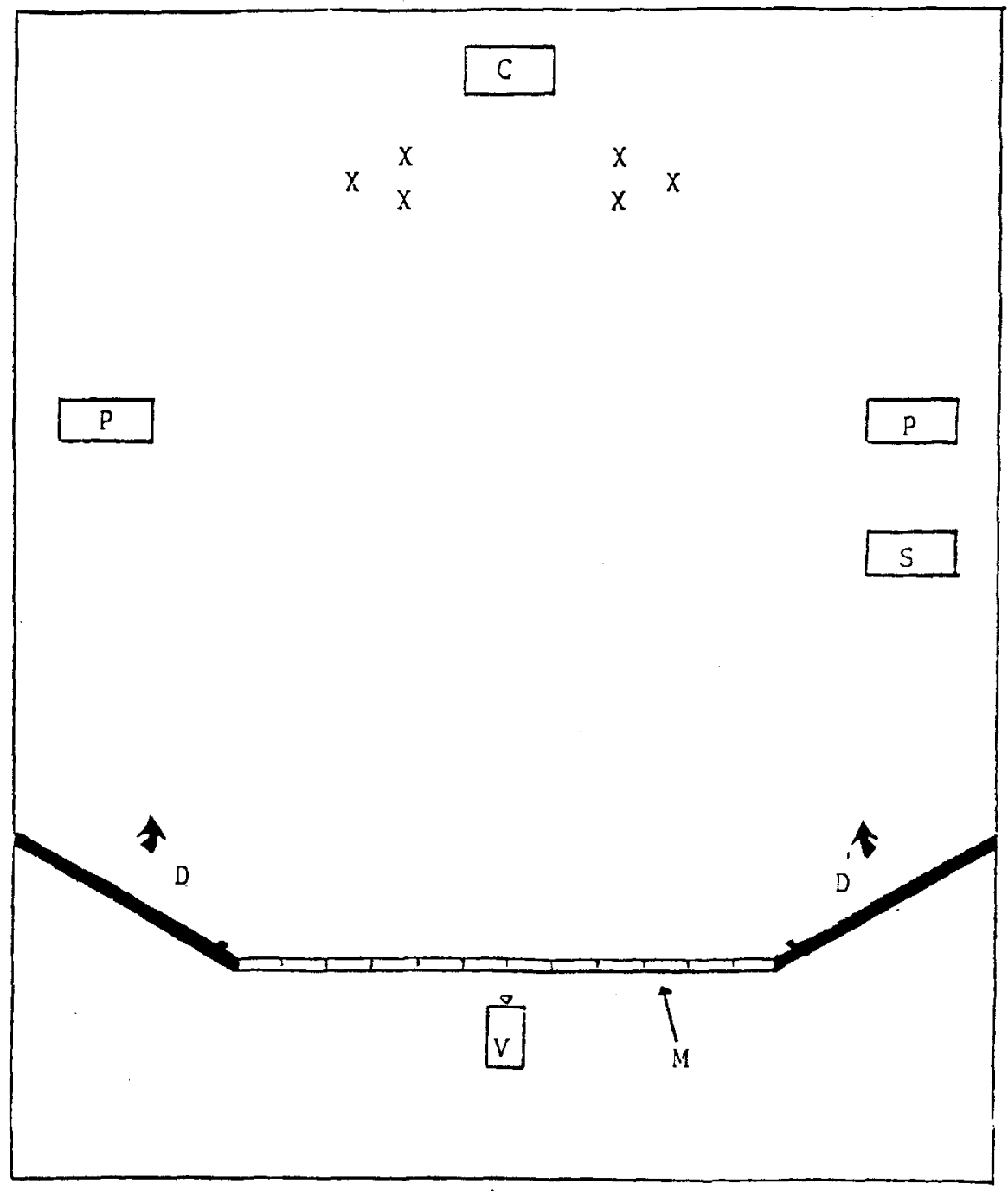

Figure I

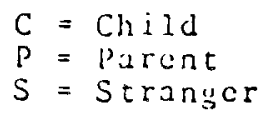

$V=V i d e o c a m e r d$

$M=$ One-way litror

$D=$ Door 


\section{Results}

\section{Exploration}

Figure II shows the levels of the three exploratory behaviors according to whether the mother or father left first at the end of Episode 3. The data for Episodes 2 and 3 are based on the whole group since no significant differences emerged between the "mother leaves first" and "father leaves first" groups before Episode 4.

All subjects explored significantly less after the stranger entered than before, boys significantly more so than girls (exploratory manipulation-boys: Sign test, $p=.03$; girls: Sigh test, $p=.37$; visual exploration: boys, $\mathrm{T}=10, \mathrm{p}=.03$, girls: $\mathrm{T}=11, \mathrm{p}=.5$ ). Compared with preseparation levels (Episode 3), exploratory locomotion was significantly lower when mother left first than father (mother, $\mathrm{T}=8$, $\mathrm{p}=.04$; father, $\mathrm{T}=11, \mathrm{p}=.3$ ). There was a nonsignificant tendency for exploratory manipulation and visual exploration to increase after father's exit but to decrease after the mother left first. Exploratory manipulation and visual exploration within Episode 4, however, were also significantly lower for those children separated from the mother first at the end of Episode 3 than from the father (exploratory manipulation: $U=12, p=.02$; visual exploration: $U=12.5, p=.02$ ). Girls were significantly lower than boys on exploratory manipulation when mother but not father left first $(U=9, p=.05)$ and boys were significantly lower than girls in visual exploration in the same circumstances $(U=3, p=.03)$. With regard to the stranger's function as a secure base, all infants showed significantly less exploratory manipulation when alone with the stranger than when together with mother, father and stranger $(T=21, p=.01-E$ pisode 3 vs. Episode 5) and there was significantly more exploratory manipulation in the presence of one parent and the stranger than when the child was left alone with stranger ( $T=21, p=.02-$ Episode 4 vs. Episode 5). When alone with the stranger in Episode 5, those children who had been separated first from the mother at the end of Episode 3 showed significantly less exploratory manipulation than those who had been separated from the father first $(U=12, p=.05)$. Compared to preseparation levels, all subjects exhibited significantly less visual exploration $(\mathrm{T}=29, \mathrm{p}=.03)$ and exploratory manipulation $(\mathrm{T}=16$, $\mathrm{p}=.005$ ) during the first reunion-Episode 2 vs. Episode 6. Girls showed this tendency in exploratory manipulation significantly $(T=0$, $\mathrm{p}=.005$ ) while boys did not. At second reunion however, all three ex- 


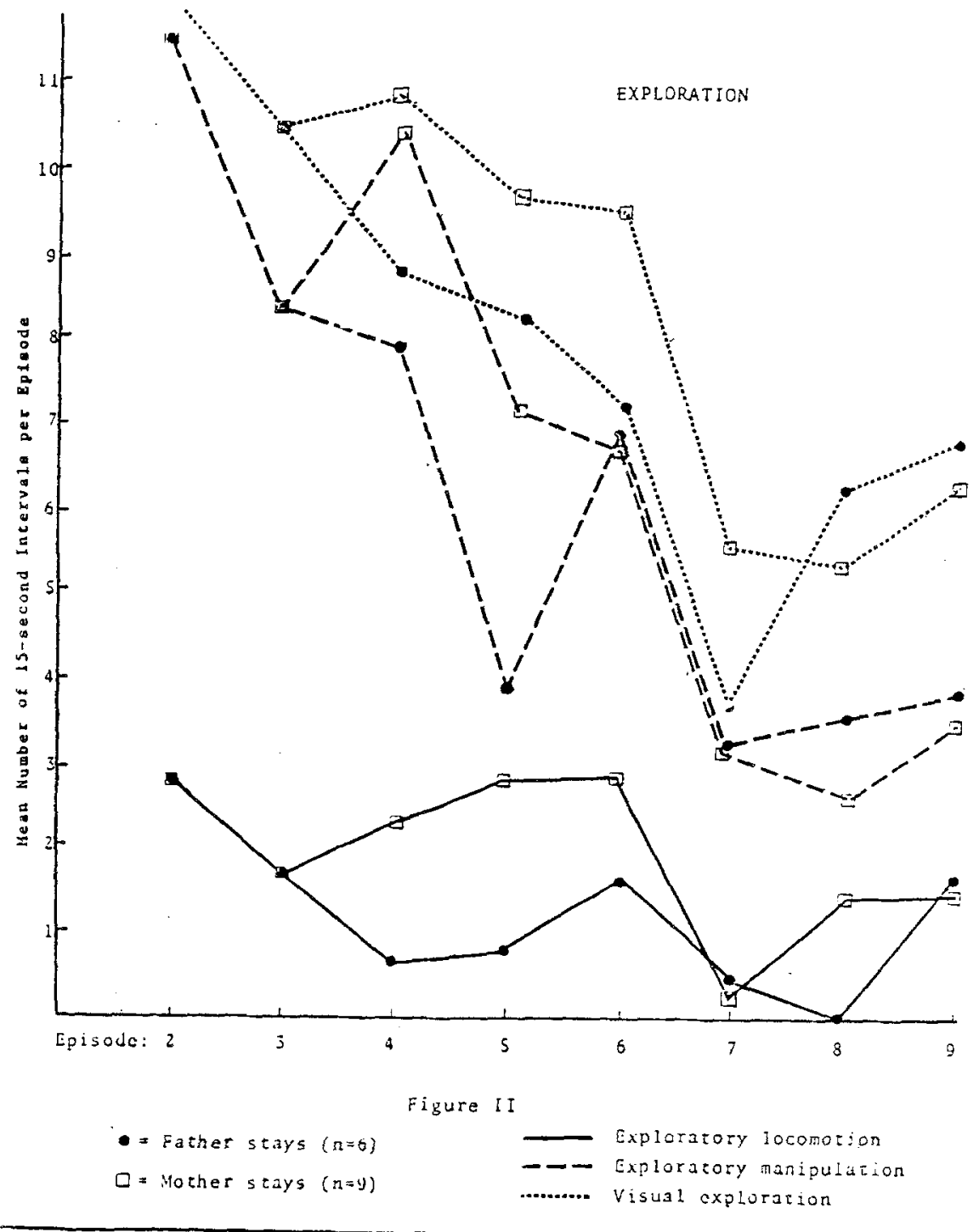


ploratory behaviors were significantly depressed and no sex differences emerged (exploratory locomotion: $T=26.5, p=.03$; exploratory manipulation: $\mathrm{T}=0, \mathrm{p}=.007$; visual exploration: $\mathrm{T}=15$, $\mathrm{p}=.005-$ Episode 2 vs. Episode 9).

\section{Attachment}

Some of our results parallel those reported by others in infantmother attachment studies ${ }^{1}$ : at no time was the stranger preferred as an attachment figure to either parent. Once the stranger entered the room (Episode 3) there was greater avoidance of $(T=36, p<.05-$ for both parents) but greater distance interaction (mother: Sign test $p<.01$; father: Sign test $p<.0002$ ) with the stranger than with either mother or father, suggesting an ambivalent curiosity towards the stranger. Boys were especially affected in this way (avoidance: Sign test $\mathrm{p}<.01$; distance interaction: Sign test $\mathrm{p}<.007)$. However, monitoring the shift in attachment behavior from pre- to post-stranger entry (Episode 2 vs. Episode 3) the infants as a group and the boys in particular showed greater proximity-seeking behavior to both mother and father (all subjects-mother: $\mathrm{T}=6, \mathrm{p}<.005$; father: $\mathrm{T}=3, \mathrm{p}<.005$. Boys-mother: $\mathrm{T}=6, \mathrm{p}<.01$; father: $\mathrm{T}=3, \mathrm{p}<.005$ ).

The infants separated first from the mother tended to seek proximity to the father more than to the stranger after the mother's departure (Median test, $\mathrm{p}=.06, \overline{\mathrm{X}}$ Prox $\mathrm{F}=3.1$; $\overline{\mathrm{X}}$ Prox. $\mathrm{S}=2.0$ ). These results were significant also only for the boys $(T=0, p<.01)$. There was no significant difference in the proximity-seeking behavior towards mother versus stranger of infants separated first from the father ( $\bar{X}$ Prox. $M=2.0$; $X$ Prox. $S=1.6$ ). These results parallel exactly the differential decrease in exploration after the mother's departure but not the father's. Children left alone with the stranger and a parent search for the departed opposite-sex parent during sequential separation $(\mathrm{U}=15.5, \mathrm{p} \leq .05$, one-tailed). These results are similar to those of Weinraub and Frankel. ${ }^{17}$

Although the effect of separation and reunion on attachment reached statistical significance only at second reunion (Episode 9), Figure III shows more proximity-seeking to mother in both groups of infants at first reunion (Episode 6) with the least being displayed to the father who stayed with the infant in Episode 4. This pattern was accentuated at the second reunion: infants separated from mother first sought proximity to mother significantly more than to father in Episode $9(T=1, p \leq .02)$. There was no difference in proximity-seeking 
to mother or father for infants separated first from father after Episode 3. The infants as a group also evidenced significantly greater proximity-seeking $(\mathrm{T}=24.5, \mathrm{p}<.04)$ and also resistance to mother than to father $(T=6.5, p<.005)$. Their distance interaction with father was also more intense than with mother $(T=8.5, \mathrm{p}<.005)$.

\section{The Attachment-Exploration Balance}

The exploration and attachment variables were measured on different scales so that their interrelationship during the sequences of the Strange Situation could not be represented graphically in raw score form on the same graph. Figure IV represents the deviations from their own means in standard score form of the exploratory manipulation, proximity-seeking-to-mother, and proximity-seeking-to-

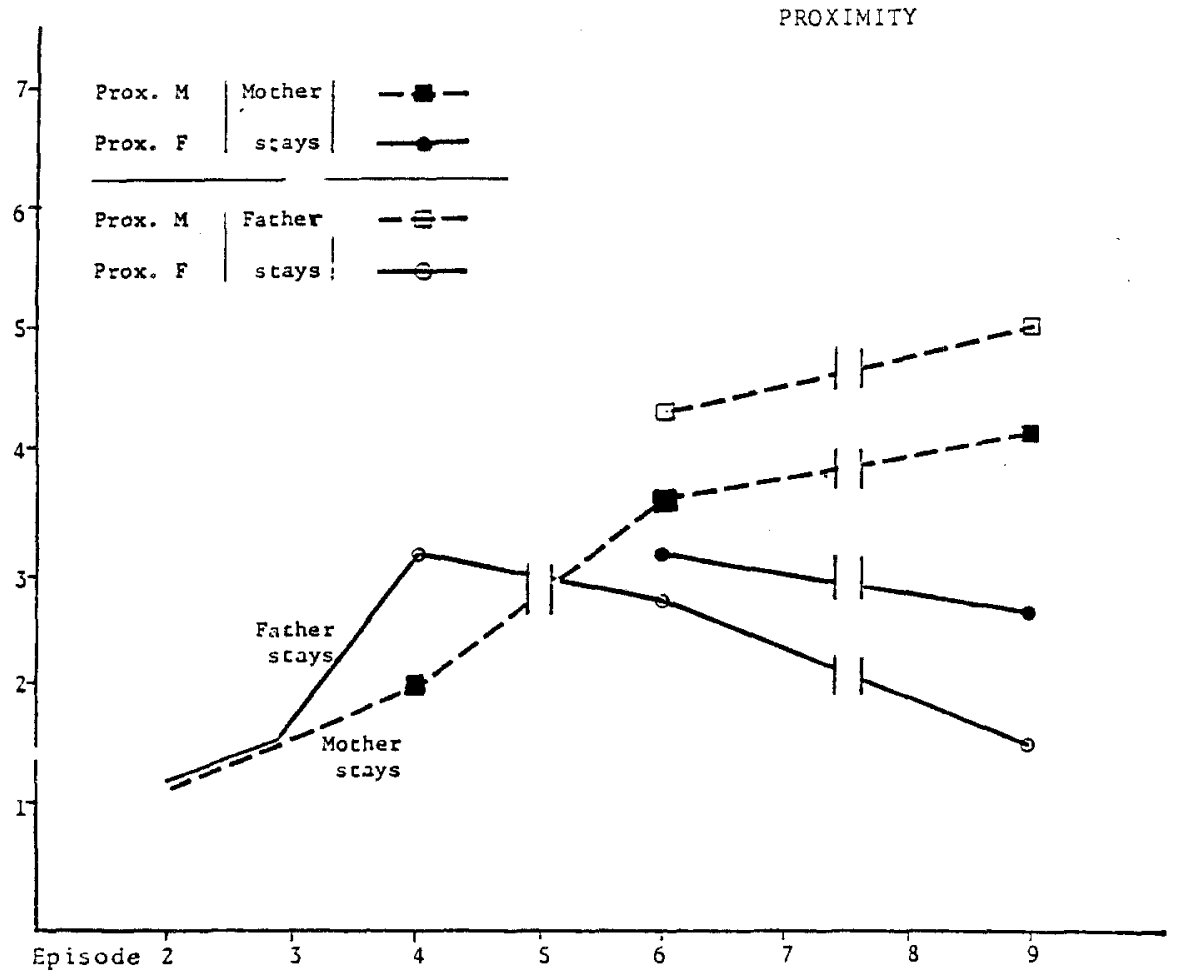




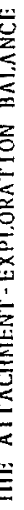

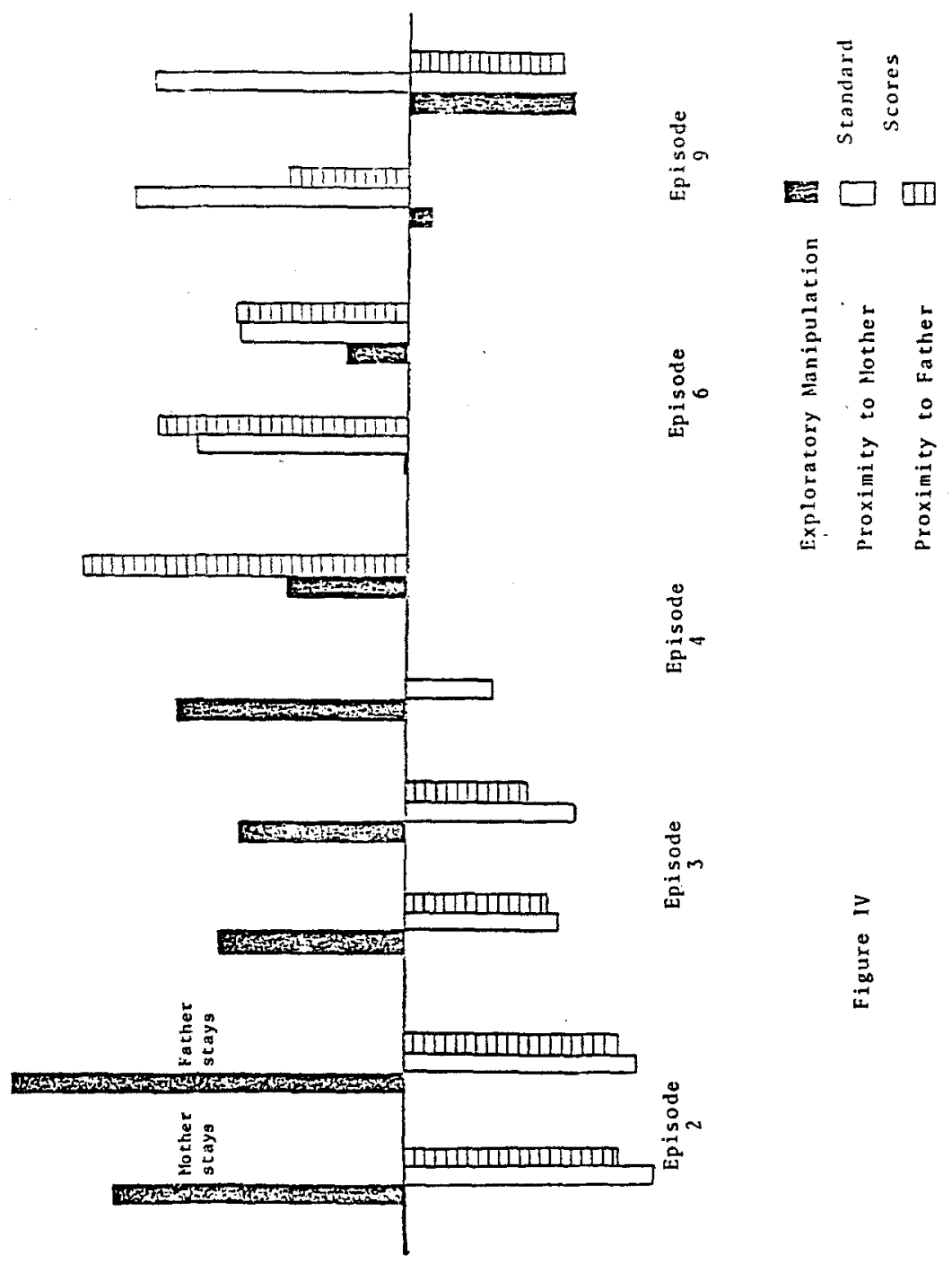


father variables. These seem to be the most sensitive indicators of the attachment-exploration balance. Data for each episode are represented by two sets of bars. The first set indicates scores for the "mother stays," the second set for the "father stays" subgroups, depending on the order of parental exit after Episode 3.

Although one still cannot compare levels of any one of these variables to any other within the same episode, Figure IV clearly illustrates the sequential decrease in exploratory behavior from about two standard deviations above its mean to almost one standard deviation below it, during the course of the Strange Situation procedure. Proximity-seeking to both mother and father generally increase consistently over the same course from a standard deviation of about 1.2 below the mean to approximately 1.5 above the mean. A notable exception occurred in Episode 9, with the extremely low proximity to father displayed by those infants separated from the mother first after Episode 3. Proximity to father immediately after mother left at the end of Episode 3 in the relevant subgroup is also at its highest level in Episode 4, compared to any other stages of procedure. By contrast, proximity to mother is still below the mean in Episode 4 for those infants separated first from the father at the end of Episode 3. While infants separated first from father explored at only their average level in Episode 6 (during first reunion), infants separated first from mother explored significantly more than this and above their own mean level during the same episode.

\section{Discussion and Conclusions}

The attachment-exploration balance in infants with mother as the primary caretaker seems more significantly affected by separation from her than from father. This is manifested primarily through the organization of exploration and proximity-seeking behavior in the context of repeated separation and reunions from both parents available simultaneously. ${ }^{15}$ This study suggests the mother's greater importance as a secure base for exploration and attachment than the father. The stranger provided neither a secure base for exploration nor an adequate alternative attachment figure. Separation from the mother lowered exploration, and heightened proximity-seeking to father. Reunion with mother, although the father was simultaneously available, increased proximity-seeking behavior to her more than to father especially for infants separated first from mother (Figure IV). 
The resistance accompanying increased proximity-seeking to mother is probably an indication of underlying anger at the separation. It is however not clear whether this should be considered a sign of possible early pathology as Ainsworth's C-classification would suggest. ${ }^{1}$ Possibly the presence of the father intensified ambivalent feelings toward the mother at the time of reunion. Further research is needed to clarify the impact of the father's simultaneous presence on infantmother attachment measures. The present findings can be suggestive only since they are based on a small sample.

The attachment-exploration balance in the behavior of the male infants in the Strange Situation seems to have been more affected than that of the female infants. While the boys evidenced significantly less exploratory manipulation after the stranger entered the room for the first time than before, the girls did not. As a direct parallel, it seems, the boys simultaneously sought greater proximity to both parents whereas the girls did not. For those infants separated first from mother, the boys, not the girls, sought greater proximity to father. While other studies ${ }^{10.11}$ have found no sex difficulties in Strange Situation behavior, our results may have been influenced by the presence of the father as an alternative attachment figure, far more familiar to the infants than a total stranger would be, as had been the case in the previous studies. These sex differences require replication with larger samples.

As the procedure goes forward, the infant's distress increases due to the cumulative and repeated separations from parents. While the level of distress is mild to moderate initially (e.g., in Episodes 4 and 5) the exploratory behaviors seem to be a sensitive indicator of differential reactions to separation from mother or father. However once the distress is intense (after Episode 5) exploratory behaviors are no longer the primary means whereby the child registers its separation distress. Possibly inhibition of exploration is a useful clinical and observational index to separation distress which is mild or moderate. On the other hand, proximity-seeking behavior clearly differentiated mother preference over father at times of greater distress. This accords with previous research suggesting that the Ainsworth classifications of the security of attachment are based primarily on infant-parent interactions at the latter stages of the Strange Situation procedure during reunion episodes. ${ }^{1.11 .16}$

This study has several implications, both theoretical and practical. From the theoretical point of view it suggests that hypothetical constructs such as "evocative memory" can be culled from the clinical 
literature and provide a useful orientation in direct experimental work. The results of this study suggest therefore that the internal version of the parent most crucial to the maintenance of exploration during the separation experiences of the infants in this study is that of mother and not father, and that separation reactions as evidenced by exploratory inhibition concern primarily the child's relationship with the mother. The continued absence of the mother from infants separated first from her caused a further inhibition in exploratory behavior, but not so in the case of infants separated first from the father. The father's presence after separation from the mother could apparently not supplement and sustain the internal image of the nurturing parent when the capacity for evocative memory is inadequately developed. ${ }^{4}$ It seems clear that the separation from mother in this Strange Situation procedure shifted the attachment-exploration balance more significantly away from exploration toward attachment than did separation from the father.

Furthermore, as regards non-parental child care, it seems that separation from a primary caretaking figure (mother) once an attachment has been formed may have at least short-term disruptive effects on exploration. The effects of daycare on attachment are not clearly established by existing studies. ${ }^{2}$ If the father cannot equal the mother as a secure base or attachment figure, what conditions are needed to make it possible for an alternative caretaker to become an adequate substitute particularly in an unfamiliar environment, (i.e., away from home in the day care center)?

Assuming that early interest in exploration is an important ingredient in cognitive development and influences subsequent school achievement, future research should assess the effect of early separations and emotional development in general over the longer term on cognitive development in children in both traditional and nontraditional child care settings. There is growing clinical recognition of the relationsihp between separation and childhood depression on the one hand, and distractibility and concentration difficulties in school on the other-especially in the middle childhood years. Children who are distractible and have concentration difficulties are often thought of as hyperkinetic (the organic syndrome) whereas recent studies suggest that they quite often have an earlier history of separation. One may speculate that the hyperactivity manifested is better described as "hyper-anxiety" which together with other factors, could be indicative of a childhood depression rather than an organic condition. ${ }^{5}$ It is essential to clarify this link between cognitive development and the child's 
emotional history - the basis of this link seems to lie, at least in part, in the attachment-exploration balance.

\section{Acknowledgements}

We wish to thank Drs. Lorraine Roccisano and Francizska Cottier for their assistance in coding the data.

\section{References}

1. Ainsworth, M., Blehar, M., Waters, E. and Wall, S. 1978. Patterns of Attachment: A Psychological Study of the Strange-Situation. Erlbaum, Hillsdale, N.J.

2. Belsky, J. \& Steinberg, L. 1978. The effects of day care: A critical review. Child Dev, 49:929-949.

3. Feldman, S. \& Ingham, M. 1975. Attachment behavior: A validation study in two age groups. Child Dev. 46:319-330.

4. Fraiberg, S. 1969. Object constancy and mental representation. Psychoanal. Study Child 24:9-47.

5. Freeman, D. \& Cornwall, T. 1980. Hyperactivity and neurosis. Amer. J. Orthopsychiat. 50:709-711.

6. Furer, M. 1975. Quoted in Mahler, M., Pine, F. \& Bergman, A. The Psychological Birth of the Human Infant. Basic Books, New York.

7. Hollingshead, A. 1975 The Four Factor Index of Social Position. Unpublished manuscript, Yale University.

8. Kotelchuck, M. 1976. The infant's relationship to the father: Experimental evidence. In M. E. Lamb (Ed.), The Role of the Father in Child Development. Wiley, New York.

9. Lamb, M. 1977. The development of mother-infant and father-infant attachments in the second year of life. Dev. Psychol. 13:637-648.

10. Lamb. M. 1978. Qualitative aspects of mother-and-father infant attachments. Infant Behavior and Development 1:265-275.

11. Main, M. \& Weston, D. 1981. The quality of the toddler's relationship to mother and father: Related to conflict behavior and the readiness to establish new relationships. Child Dev, 52:932-940.

12. Osofsky, J. \& Connors, K. 1979. Mother-infant interaction: An integrative view of a complex system. In J. D. Osofsky (Ed.) Handbook of Infant Development. John Wiley, New York.

13. Sroufe, L. 1979. Socioemotional development. In J. D. Osofsky (Ed.) Handbook of Infant Development. John Wiley, New York.

14. Sroufe, L. \& Waters, E. 1977. Attachment as an organizational construct. Child Dev. 48:1184-1199.

15. Tracy, R., Lamb, M. \& Ainsworth, M. 1976. Infant approach behavior as related to attachment. Child Dev. 47:571-578.

16. Waters, $\mathrm{E}$. 1978. The reliability and stability of individual differences in infantmother attachment. Child Dev. 49:483-494.

17. Weinraub. M. \& Frankel, J. 1977. Sex differences in parent-infant interaction during free play, departure and separation. Child Dev. 48:1240-1249.

18. Winnicott, D. 1958. The capacity to be alone. Int. J. Psychoanal. 39:416-420. 